\title{
Is large femoral head a better option than a conventional femoral head primary total hip arthroplasty in Indian population
}

\author{
Hiranya Kumar Seenappa, Karthik Mittemari Naraynamurthy, \\ Rasiq Rashid*, Shivraj Nadagouda, Vamshhikrishna Chand
}

\begin{abstract}
Department of Orthopaedics, Vydehi Institute of Medical Sciences and Research Centre, Whitefield, Bengaluru, Karnataka, India
\end{abstract}

Received: 29 November 2020

Accepted: 31 December 2020

*Correspondence:

Dr. Rasiq Rashid,

E-mail: drrasiq@gmail.com

Copyright: ( ) the author(s), publisher and licensee Medip Academy. This is an open-access article distributed under the terms of the Creative Commons Attribution Non-Commercial License, which permits unrestricted non-commercial use, distribution, and reproduction in any medium, provided the original work is properly cited.

\begin{abstract}
Background: Study aimed to assess and compare the functional outcome in patients underwent the large femoral head THA and conventional femoral head THA.

Methods: It is a comparative prospective cross sectional study conducted among the patients undergoing primary total hip arthroplasty through postero-lateral approach at department of orthopaedics Vydehi institute of medical sciences, Bengaluru during the period of July 2017 to July 2019. Patients aged between 18-80years of both genders undergoing Primary THA for Osteoarthritis (OA), Rheumatoid Arthritis (RA), Ankylosing Spondylitis (AS), Post traumatic arthritis, Avascular necrosis (AVN), Acute fracture neck of femur, Non-union fracture neck of femur (NOF). Patients undergoing primary total hip arthroplasty in Intertrochanteric fracture, Acetabular fracture and patients undergoing Revision Hip Arthroplasty were excluded from study. Patients were grouped as the ones treated with large femoral head THA and conventional femoral head THA.

Results: This series consisted of 36 patients with 44 diseased hips treated with primary total hip arthroplasty (THA). Out of 36 patients, 9 patients (25\%) belonged to an age group of below 30 years of age, 10 patients $(27.8 \%)$ belonged to the age group between 31-40 years of age, 8 patients $(22.2 \%)$ belonged to the age group 41-51 years of age and 9 patients (25\%) belonged to age group of 51-60 years of age. The mean level of Modified Harris Hip score and improvement of movements in all planes was found to be statistically significantly in the patients treated with large femoral head primary THA compared to those treated with conventional method. $(\mathrm{p}<0.001)$

Conclusions: Study has shown improved functional outcome (Modified harris hip score) and range of movement in the patients treated with the large femoral head primary THA as compared to those treated with a conventional femoral head.
\end{abstract}

Keywords: Total hip arthroplasty, Conventional femoral head, Large femoral head, Modified harris hip score, Range of movement

\section{INTRODUCTION}

Total hip replacement (THR) is a highly successful treatment for various end stage hip conditions; it can alleviate pain, restore function, stability and enhance quality of life by replacing the diseased articular surfaces with synthetic material. ${ }^{1}$ Since their initial launch, the configuration of complete hip arthroplasty (THA) implants has advanced steadily. ${ }^{2}$ The diameter of the prosthetic femoral head is one of the key components of THA design. Use of bigger femoral head size in total hip arthroplasty (THA) has increased during the past decade; $32 \mathrm{~mm}$ and $36 \mathrm{~mm}$ are the most commonly used femoral head sizes, as reported by several arthroplasty registries. ${ }^{3-4}$ The risk of dislocation is lower as the head diameter increases, has been well established. But head diameter impacts other 
factors outside the integrity of the joint like increased wear and tear. But after introduction of highly cross-linked polyethylene and hard-on-hard bearings has enabled surgeons to implant large diameter heads which eliminate the risk of dislocation almost entirely along with improvement in range of motions and the Modified Harris Hip score in the patients. ${ }^{5-6}$ Some studies have shown wear is independent of head size when electron- beam irradiated, highly cross-linked, and melted UHMWPE represent as a liner. ${ }^{7-8}$ Nearly all of the hip and knee implants manufactured are mostly designed for Western patients to allow them to perform activities of daily life like sitting at the table to eat, climb stairs, and use western commode toilet and shower independently. ${ }^{9}$ Still, it is disputable whether it serves the expected needs of the Asian and African patients who represent almost half of the world population. Most Asian patients undergoing THA would like to squat and sit cross-legged on the floor or bed. This need may be fulfilled with the use of large femoral heads as it increases the implant head to neck ratio, increases RoM, reduces component impingement, and reduces dislocations by increasing jump distance. ${ }^{10-12}$ This encouraged the use of more anatomic head diameter, which leads to improvement in range of motion, improvement in activities of daily living, reduced impingement, reduced subluxation, reduced dislocation, improved treatment, prevention of recurrent dislocation, and greater forgiveness even in positioning the acetabular component. ${ }^{13}$ Harris Hip Score (HHS) is a validated and most commonly used instrument for measuring an individual's functional ability before and after surgery. ${ }^{14}$ Study aimed to assess and compare the functional outcome in patients underwent the conventional femoral head primary THA and large femoral head primary THA.

\section{METHODS}

This study was conducted among the patients undergoing primary hip arthroplasty through postero-lateral approach at department of orthopaedics at Vydehi Institute of medical science and research centre, Bengaluru during the period of July 2017 to July 2019. Ethics clearance was obtained prior to recruitment of the patients for study. Patients were included in present study after obtaining the informed consent. Patients aged between 18-80years of both genders undergoing Primary Hip Arthroplasty for Osteoarthritis (OA), Rheumatoid Arthritis (RA), Ankylosing Spondylitis (AS), Post Traumatic Arthritis, Avascular necrosis (AVN), Acute Fracture Neck of Femur, Non-Union Fracture Neck of Femur (NOF). Patients undergoing primary total hip arthroplasty in intertrochanteric fracture, acetabular fracture and patients undergoing revision hip arthroplasty were excluded from study. The patients were evaluated clinically, radiologically and functional outcome was assessed using modified Harris hip score before surgery and at 6 weeks, 12 weeks postoperatively, and at 2 years of final follow up.

The data were entered in Microsoft Excel and analyzed with IBM Statistical package for social sciences (SPSS) statistics software 23.0 Version. To describe the data descriptive statistics frequency analysis, percentage analysis was used and for categorical variables the mean and standard deviation (S.D) were used for continuous variables. To find the significant difference between the bivariate samples in Independent groups the unpaired sample t-test was used. In all the above statistical tools the probability value 0.05 is considered as significant level.

\section{RESULTS}

This series consisted 44 diseased hips in 36 patients treated with primary total hip arthroplasty (THA). Out of 36 patients, 9 patients $(25 \%)$ belonged to an age group of below 30 years of age, 10 patients $(27.8 \%)$ belonged to the age group between $31-40$ years of age, 8 patients $(22.2 \%)$ belonged to the age group 41-51 years of age and 9 patients (25\%) belonged to age group of 51-60 years of age. In our study, the youngest patient was 23 years old and the oldest patient was 60 years old. The mean age at the time of operation was 40.16 years (Table 1 ).

Table 1: Demographic details of the patients.

\begin{tabular}{|c|c|c|c|}
\hline & & Frequency & $\%$ \\
\hline \multirow{3}{*}{$\begin{array}{l}\text { Age wise } \\
\text { (in years) }\end{array}$} & $<30$ & 9 & 25 \\
\hline & $31-50$ & 18 & 50 \\
\hline & $>50$ & 9 & 25 \\
\hline \multirow{2}{*}{ Gender } & Male & 23 & 63.9 \\
\hline & Female & 13 & 36.1 \\
\hline \multirow{2}{*}{$\begin{array}{l}\text { Side } \\
\text { effected }\end{array}$} & Left & 21 & 47.7 \\
\hline & Right & 23 & 52.3 \\
\hline \multirow{2}{*}{$\begin{array}{l}\text { Femoral } \\
\text { Head Size }\end{array}$} & LFH & 22 & 50 \\
\hline & Conventional & 22 & 50 \\
\hline \multirow{7}{*}{ Diagnosis } & $\begin{array}{l}\text { Ankylosing } \\
\text { spondilitis }\end{array}$ & 7 & 15.9 \\
\hline & AVN & 15 & 34.1 \\
\hline & $\begin{array}{l}\text { Inflammatory } \\
\text { arthritis }\end{array}$ & 8 & 18.2 \\
\hline & $\begin{array}{l}\text { Non-union } \\
\text { NOF }\end{array}$ & 9 & 20.5 \\
\hline & $\begin{array}{l}\text { Post traumatic } \\
\text { arthritis }\end{array}$ & 3 & 6.8 \\
\hline & $\mathrm{DDH}$ & 1 & 2.3 \\
\hline & Acute NOF & 1 & 2.3 \\
\hline
\end{tabular}

LFH - Large femoral head; AVN - Avascular Necrosis; NOF Neck of Femur.

In conventional femoral head group $12(54.2 \%)$ hips had right-sided affection and $10(45.5 \%)$ hips had left-sided affection. Whereas in large femoral head group 11 (50.0\%) hips had right-sided affection and $11(50.0 \%)$ hips had leftsided affection. Overall, $23(52.3 \%)$ hips were operated on the right side and $21(47.7 \%)$ hips were operated on the left side. And only 8 patients were operated bilaterally and 28 patients were operated unilaterally. The most common indication for surgery in our study groups was osteoarthritis secondary to AVN in 15 (34.1\%) hips, other indications were fracture non-union of femoral neck in 9 
(20.5\%) hips, inflammatory arthritis in $8(18.2 \%)$ hips, ankylosing spondylitis in 7 hips $(15.9 \%)$, post-traumatic arthritis in 3 (6.8\%) hips, 1 (2.3\%) hip with DDH and 1 $(2.3 \%)$ hip with acute fracture neck of femur.

Table 2: Range of movements and modified Harris hip score in both groups at follow-up.

\begin{tabular}{|c|c|c|c|c|}
\hline & & Conventional & LFH & P value \\
\hline \multirow{3}{*}{ Flexion } & $6^{\text {th }}$ week & $87.27 \pm 6.12$ & $97.73 \pm 6.12$ & $0.001 *$ \\
\hline & $12^{\text {th }}$ week & $90.91 \pm 6.66$ & $104.09 \pm 7.01$ & $0.001 *$ \\
\hline & 2 years & $91.82 \pm 6.64$ & $104.09 \pm 7.05$ & $0.001 *$ \\
\hline \multirow{3}{*}{ Extension } & $6^{\text {th }}$ week & $7.95 \pm 4.27$ & $10.91 \pm 2.51$ & $0.008^{*}$ \\
\hline & $12^{\text {th }}$ week & $8.41 \pm 4.73$ & $11.59 \pm 2.84$ & $0.011^{*}$ \\
\hline & 2 years & $8.41 \pm 4.73$ & $11.59 \pm 2.84$ & $0.01 *$ \\
\hline \multirow{3}{*}{ Adduction } & $6^{\text {th }}$ week & $23.41 \pm 6.05$ & $27.73 \pm 3.69$ & $0.007^{*}$ \\
\hline & $12^{\text {th }}$ week & $23.64 \pm 5.60$ & $27.27 \pm 4.0$ & $0.017^{*}$ \\
\hline & 2 years & $23.64 \pm 5.6$ & $27.50 \pm 4.3$ & $0.014 *$ \\
\hline \multirow{3}{*}{ Abduction } & $6^{\text {th }}$ week & $33.86 \pm 5.1$ & $37.86 \pm 3.36$ & $0.008^{*}$ \\
\hline & $12^{\text {th }}$ week & $34.77 \pm 4.99$ & $38.41 \pm 2.38$ & $0.017^{*}$ \\
\hline & 2 years & $34.77 \pm 4.99$ & $38.41 \pm 2.38$ & $0.014^{*}$ \\
\hline \multirow{3}{*}{ Internal rotation } & $6^{\text {th }}$ week & $20.91 \pm 5.26$ & $27.73 \pm 3.35$ & $0.001 *$ \\
\hline & $12^{\text {th }}$ week & $21.14 \pm 5.1$ & $28.41 \pm 2.84$ & $0.001 *$ \\
\hline & 2 years & $21.14 \pm 5.1$ & $28.41 \pm 2.81$ & $0.001 *$ \\
\hline \multirow{3}{*}{ External rotation } & $6^{\text {th }}$ week & $25.91 \pm 4.26$ & $35.23 \pm 3.93$ & $0.001 *$ \\
\hline & $12^{\text {th }}$ week & $27.73 \pm 4.81$ & $36.59 \pm 3.23$ & $0.001 *$ \\
\hline & 2 years & $27.73 \pm 4.81$ & $36.59 \pm 3.23$ & $0.001 *$ \\
\hline \multirow{3}{*}{ Modified Harris score } & $6^{\text {th }}$ week & $36.65 \pm 9.62$ & $42.15 \pm 13.26$ & $0.01 *$ \\
\hline & $12^{\text {th }}$ week & $57.5 \pm 15.57$ & $66 \pm 16.55$ & $0.001 *$ \\
\hline & 2 years & $85.65 \pm 12.37$ & $92.90 \pm 13.65$ & $0.001 *$ \\
\hline
\end{tabular}

$* \mathrm{p}$-value $<0.05$ is considered statistically significant and $\mathrm{p}<0.001$ is statistically highly significant.

Table 3: Comparison of other studies with our study with similar results.

\begin{tabular}{|lllll|}
\hline & Large Femoral Head THA & \multicolumn{2}{c|}{ Conventional Femoral Head THA } \\
\hline & $\begin{array}{l}\text { Mean of Modified } \\
\text { Harris Hip score } \\
\text { Initially }\end{array}$ & $\begin{array}{l}\text { Mean of Modified Harris } \\
\text { Hip score } \\
\text { Last follow-up }\end{array}$ & $\begin{array}{l}\text { Mean of Modified } \\
\text { Harris Hip score } \\
\text { Initially }\end{array}$ & $\begin{array}{l}\text { Mean of Modified } \\
\text { Harris Hip score } \\
\text { Last follow-up }\end{array}$ \\
\hline $\begin{array}{l}\text { Our study (n=44 } \\
\text { hips) }\end{array}$ & 42 & 92 & 39 & 85 \\
\hline $\begin{array}{l}\text { Johannes F P } \\
\text { et.al.,28 } \text { (n=52 hips) }\end{array}$ & 32 & 90 & 30 & 83 \\
\hline $\begin{array}{l}\text { Gupta } \\
\text { Lokeshet.al., } \\
\text { (n=20 hips) }\end{array}$ & 35 & 90 & 32 & 86 \\
\hline
\end{tabular}

In our study, the most common type of THA done was uncemented in 36 hips $(81.8 \%)$ in which 16 hips $(72.7 \%)$ were from the conventional group and 20 hips $(90.8 \%)$ from the LFH group. And for 1 hips (2.3\%) in conventional group cemented, 1 hip $(2.3 \%)$ in LFH group hybrid and 6 hips (13.6\%) (5 in conventional group and 1 in LFH group) reverse hybrid THR was done. Majority of hips $36(81.8 \%)$ were operated under combined spinalepidural anaesthesia. Only $8(18.2 \%)$ hips were operated under general anaesthesia and majority of them were suffering from ankylosing spondylitis. Periprosthetic fracture of a femoral shaft while implanting the femoral stem was seen in 1 hip with conventional femoral head cemented THR, which was treated with locking plate and
SS wire encirclage and patient was on strictly non-weightbearing walk for 4 weeks and 1 hip from LFH uncemented THR had a greater trochanter fracture while reduction. The patient was treated conservatively with bed rest and nonweight-bearing walk for 6 weeks.

Two patients from the LFH group developed lengthening of the operated limb ( $<2 \mathrm{cms}$ ) and 2 patients ( 1 from each group) developed shortening of the operated limb, which was treated with shoe-rise on the shorter side. 2 patients ( 1 from each group) developed a superficial wound infection (SWI) which were treated with superficial wound debridement and extended the antibiotic course. In our study, 15 days was the mean stay in the hospital for the 
patients with conventional femoral head THA and 16 days for the patients with LFH-THA and there was no statistical significance with $\mathrm{p}>0.05$.

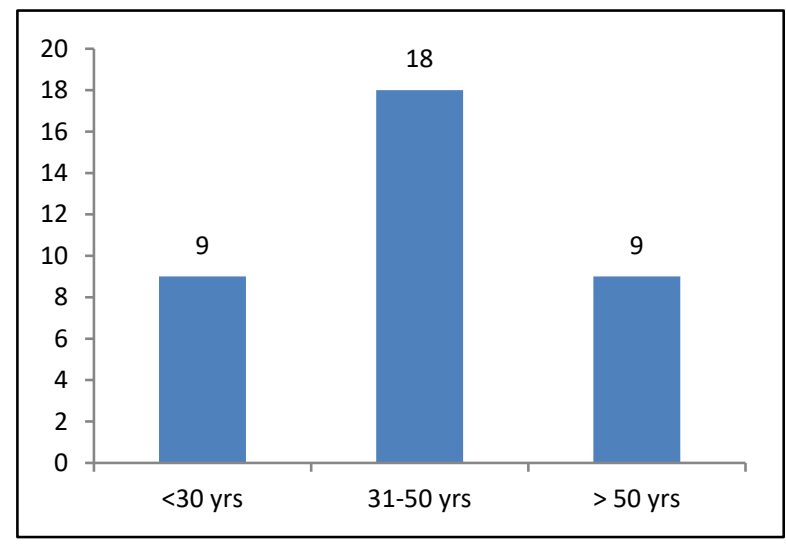

Figure 1: Age-wise distribution of the patients.

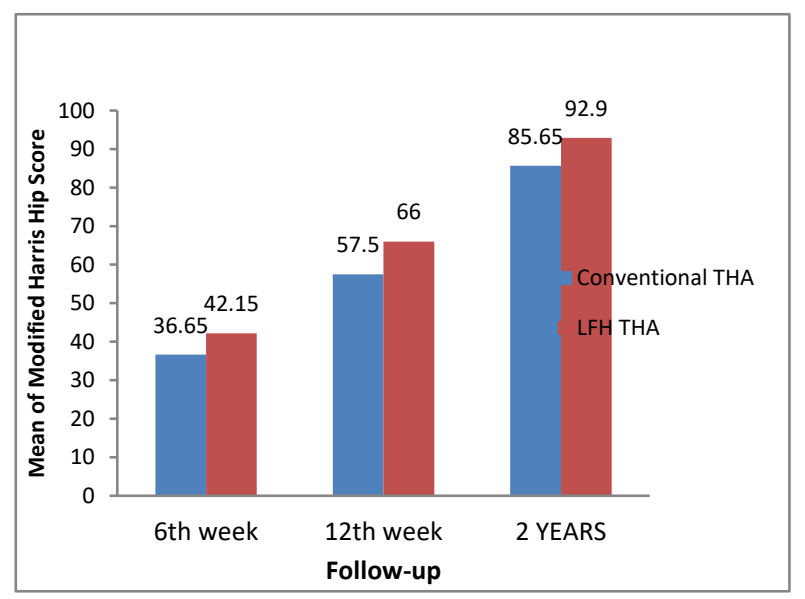

Figure 2: Comparison of modified Harris hip score.

Primary THR showed better result in the LFH (32 $\mathrm{mm}$ and $36 \mathrm{~mm}$ ) group compared to the patients grouped in conventional $(28 \mathrm{~mm})$ femoral head. These findings were consistent with each follow-up at 6 th week, 12 th week and 2 years postoperatively. At final follow up the modified Harris Hip score improved from $42.15 \pm 13.26$ at 6 weeks post operatively to $92.9 \pm 13.65$ at the end of 2 years in LFH group and from $36.65 \pm 9.62$ at 6 weeks to $85.65 \pm 12.37$ at the end of 2 years in conventional group. The overall range of movement in all planes with the large femoral head THA was significantly better than the patients with conventional femoral head THA (Table 2).

\section{DISCUSSION}

The surgery aims at relieving pain, maintaining joint mobility and stability. The size of the femoral head is one of the most significant factors under the surgeon's control. ${ }^{15}$ The recorded incidence of dislocation from Primary Total Hip Arthroplasty is 0.6 per cent with $36 \mathrm{~mm}$ (large head) and 6.4 per cent with $28 \mathrm{~mm}$ (standard head) femoral head size. ${ }^{16}$ Resetting optimum ROM after THA is crucial to enhancing the functional outcome of the patient. Large femoral heads have become popular in recent years because of their advantage of greater stability and impingement-free ROM over conventional heads due to improved material properties and wear characteristics of highly cross-linking polyethylene and ceramics of the fourth generation. ${ }^{11,17}$

The study was conducted in 36 patients with 44 hips treated with primary THA through posterolateral approach for various hip conditions between the ages of 18-80 years. Of the 36 patients included in the study, 23 (63.9\%) were males and $13(36.1 \%)$ were females at the time of surgery, with a mean age of 40 years (23-60 years) (Table 1$)$.

The sample size was calculated with following assumptions of Expected proportion $=0.0005$; Precision $=1$; $\mathrm{CI}=95 \%$ and the formula used was: $\mathrm{n}=[\mathrm{Z} 2(1-\alpha / 2) \mathrm{P}(1-\mathrm{p})]$ /d2 , Where, n:sample size; P: expected proportion; d: absolute precision and $\mathrm{Z}(1-\alpha / 2)=\mathrm{CI}$.

All the patients were followed regularly at 6 weeks, 12 weeks and at the end of 2 years follow up and were assessed both radiologically and clinically at each followup. Results were analyzed both clinically and radiologically. Out of 36 patients included in the study, 23 $(63.9 \%)$ were males and $13(36.1 \%)$ were females with a mean age of 40 years (23-60 years) at the time of surgery. Uncemented THR was done in $36(81.8 \%)$ hips, reverse hybrid in $6(13.6 \%)$ hips, hybrid in $1(2.3 \%)$ hip and cemented in $1(2.3 \%)$ hip. 100 elevated acetabular liner was used in all cases. There was no significant statistical difference regarding age, side operated, type of THA performed, type of anaesthesia used, intraoperative or postoperative complications and duration of stay in the hospital between the two groups.

Recent trend is changing towards the use of large femoral heads as American Joint Replacement Registry (3rd) 2016 annual report data shows that femoral head size of $36 \mathrm{~mm}$ has remained relatively constant between 2012 and 2015, and was used in approximately $50 \%$ of the total hip arthroplasties performed because of increased stability with large femoral heads. ${ }^{3}$

Cho et al did a review study on using large femoral heads in total hip arthroplasty in 2016 and their study showed femoral head sizes larger than $32 \mathrm{~mm}$ offer multiple advantages in physical function and activity levels of patients by improving hip stability, decreasing dislocations rates and increasing range of motion (ROM). ${ }^{10}$

Singh et al conducted a retrospective study on head size and dislocation rate in primary hip arthroplasty and followed 317 primary Total Hip Arthroplasties (THA's) performed in 281 patients between January 2006 and December 2009 with $36 \mathrm{~mm}$ (group A) and $28 \mathrm{~mm}$ (group B) diameter femoral head through postero-lateral approach. ${ }^{16}$ 

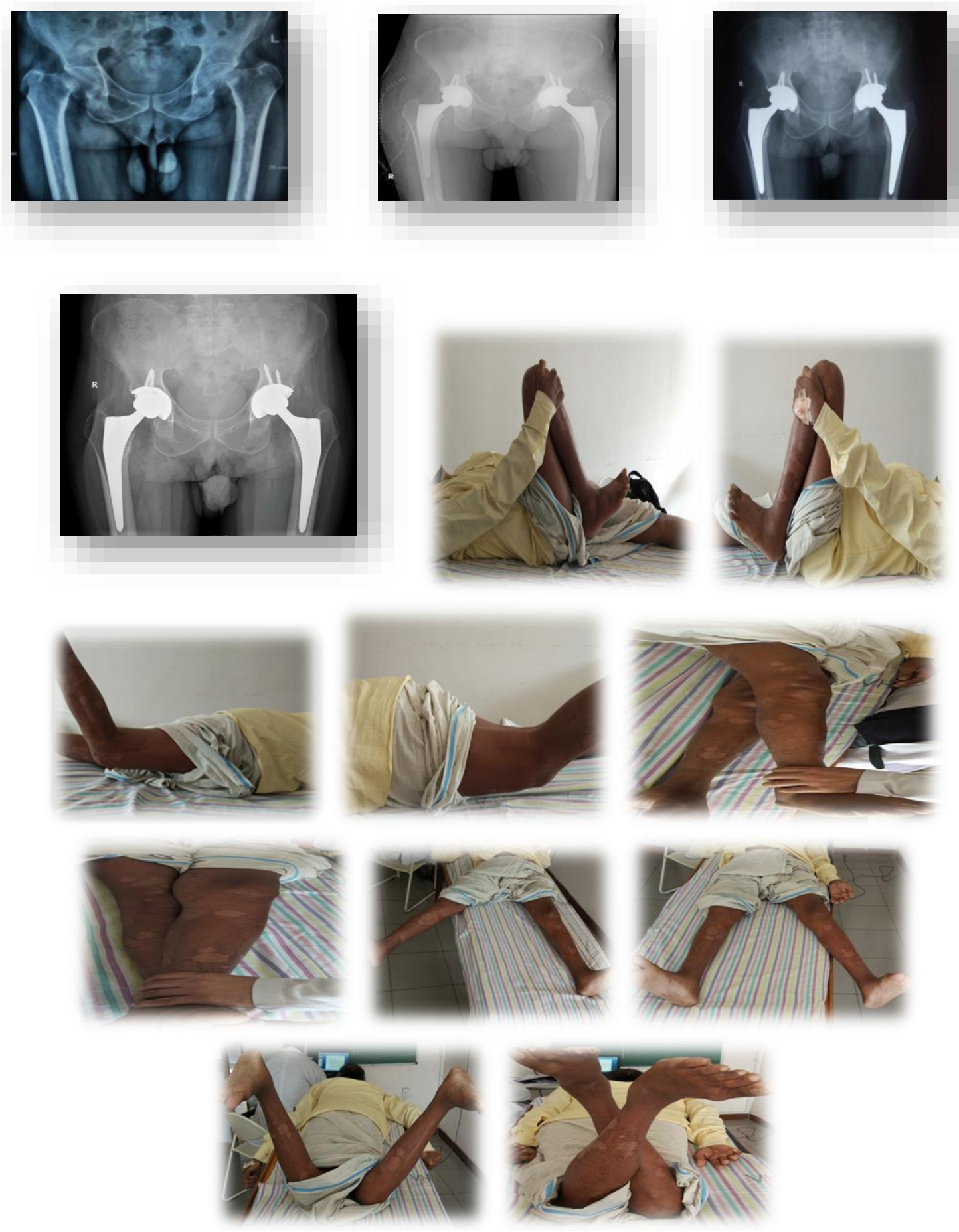

Figure 3: Case result right side $32 \mathrm{~mm}$ head and left side $28 \mathrm{~mm}$ head.

Howie et al conducted a randomized control trial study of 644 patients from September 2001 to June 2007 and found the incidence of dislocation within one year after primary hip arthroplasty was five times lower in patients with 36 $\mathrm{mm}$ articulation $(0.8 \%)$ than in those with $28 \mathrm{~mm}$ articulation (4.4\%). ${ }^{18}$

Amlie et al conducted a retrospective cohort study in 2572 primary THA's performed through a postero-lateral approach with a $28 \mathrm{~mm}$ or $32 \mathrm{~mm}$ diameter femoral head in the period of study from February 2002 to July 2009. ${ }^{19}$ They found dislocation in 49 hips $(3.1 \%)$ with $28 \mathrm{~mm}$ femoral head and in 4 hips $(0.4 \%)$ with a $32 \mathrm{~mm}$ femoral head.

However, Magee et al conducted a retrospective study on effect of femoral head diameter on risk of dislocation after primary hip arthroplasty and followed 527 total hip 
arthroplasties in 469 patients between January 2001 to August 2010 with femoral head sizes ranging from 28 to $44 \mathrm{~mm}$ performed by a single surgeon (Aaron A Hofmann) in department of orthopaedics at University of Utah, USA using posterior approach in all patients. ${ }^{20}$ The patients were followed at defined intervals but there was found no statistically significant association between the risk of dislocation and femoral head size.

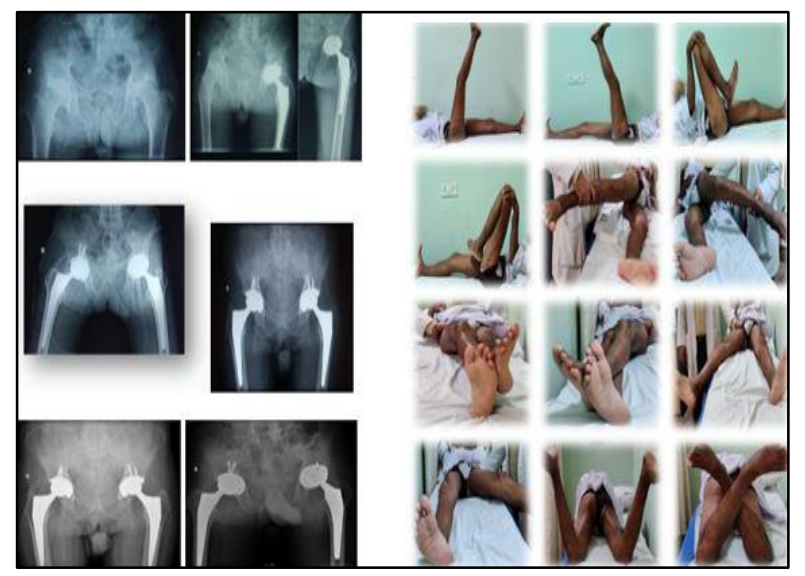

Figure 4: Case result B/L $36 \mathrm{~mm}$ head.

Wokim et al conducted a study involving 543 patients who underwent primary Total Hip Arthroplasty (THA) and revision hip arthroplasty using the postero-lateral approach in the author's hospital from January 2000 to December 2014 and were followed for a minimum of 6 months. ${ }^{21}$ Primary hip arthroplasty was performed in 407 cases and revision hip arthroplasty was performed on 136 patients. A $28 \mathrm{~mm}$ diameter femoral head was used in 367 cases and femoral heads size larger than $32 \mathrm{~mm}$ were used in 176 cases. Dislocation occurred in 36 hips $(9.8 \%)$ in the $28 \mathrm{~mm}$ head size group and 16 hips $(9.1 \%)$ in the group with greater than $32 \mathrm{~mm}$ head size which they also found statistically insignificant. They concluded that patientrelated risk factors have a greater impact on dislocations rather than head size.

Lavigne et al conducted a cohort study between February 2006 and May 2007 on 165 patients undergoing primary THA through posterior approach under age of $<65$ years and found that LDH-THA offers better hip ROM compared to $28 \mathrm{~mm}$ THA, which is most likely due to a combination of a favourable prosthetic head neck diameter ratio and optimal hip stability and significantly greater total arcs of motion (approximately $20^{\circ}$ ), mostly due to an increase of hip flexion and external rotation. ${ }^{22}$

Sultan et al demonstrated that there was an average was an increase of $8.1^{\circ}$ in the amount of IR needed to cause posterior dislocation in patients with $32 \mathrm{~mm}$ head when compared with patients receiving a $28 \mathrm{~mm}$ head. ${ }^{23}$

Burroughs et al conducted an in vitro experimental study in Orthopedic Biomechanics and Biomaterials Laboratory, Massachusetts General, Hospital, Boston, Mass in 2002 and studied the effect of larger femoral head sizes for total hip arthroplasty on the type of impingement, range of motion (ROM), and joint stability using an anatomic fullsize hip model (anatomic Goniometer) and a novel anatomic dislocation simulator with $28,32,38$ and $44 \mathrm{~mm}$ femoral heads. They observed that the $38 \mathrm{~mm}$ and $44 \mathrm{~mm}$ head virtually eliminate component-to-component impingement. ${ }^{24}$ Whereas, component-to-component impingement occurred in $60 \%$ of all cases tested with the $28 \mathrm{~mm}$ head and $47 \%$ of the cases tested with the $32-\mathrm{mm}$ head. Femoral heads of $38 \mathrm{~mm}$ and $44 \mathrm{~mm}$ had an advantage in pure flexion of about 120 versus the $28 \mathrm{~mm}$ head with a skirt, and advantage of about 70 versus the 32 $\mathrm{mm}$ head with a skirt. And an increase in femoral-head size led to an increase in the amount of translation required to produce a dislocation (jump distance).

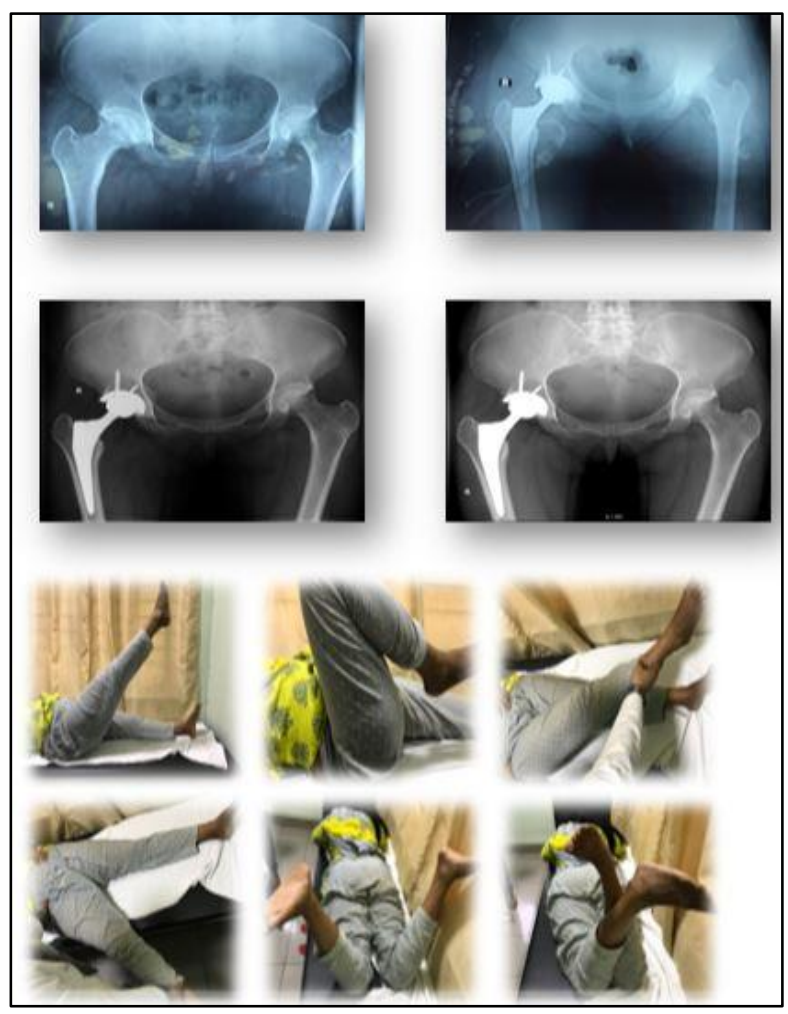

Figure 5: Case result $32 \mathrm{~mm}$ head.

Barrack et al in a ROM simulation with digitized implants and virtual reality software, found an improvement of 8 degrees of hip flexion when head size was increased from 28 to $32 .^{25}$

Whereas, Bartz et al reported only very small gains in movement before impingement when the head size increased from 22 to $28 \mathrm{~mm}$ and no significant increase between 28 and 32 mm heads. ${ }^{26}$

Hammerberg et al conducted a prospective study on 94 uncemented primary total hip arthroplasties in 84 patients (47 men and 37 women) operated through posterior approach in 2003 with average age of $65.1 \pm 9.8$ years and mean follow up of $3.6 \pm 0.7$ years and found that there was 
no statistical difference in range of motion in relation to head size between $28 \mathrm{~mm}, 32 \mathrm{~mm}$, and $38 \mathrm{~mm}, 44 \mathrm{~mm} \cdot{ }^{27}$ However, they also found that there was no difference in linear wear with increasing femoral head size.

In our study, a statistically significant improvement in the range of motion was noted in all planes in LFH-THA as compared to conventional femoral head THA. The flexion was increased by 12.27 degrees, extension by 3.18 degrees, adduction by 3.86 degrees, abduction by 3.64 degrees, internal rotation by 7.27 degrees and external rotation by 8.86 degrees in patients who received large ( 32 $\mathrm{mm}$ and $36 \mathrm{~mm}$ ) femoral head as compared to the patients who received conventional $(28 \mathrm{~mm})$ femoral head at the end of follow up. However, we have not seen any dislocations in either of the groups for which we think the credit goes to the experience of the operating surgeons, improved posterior capsule and soft tissue repair along with the use of elevated acetabular liners.

In present study, there is statistically significant better results in range of movement in patients underwent the primary THA with large femoral head compared to the conventional femoral head. These findings were consistent with various studies. . $^{1,22,24,25,29}$

And modified Harris Hip score showed a better result in the LFH group compared to the patients grouped in conventional femoral head. These findings were consistent with each follow-up at 6th week, 12th week, 2 years postoperatively. These were in concordance with other studies. $^{1,28}$ (Table 3).

\section{CONCLUSION}

Our study shows Modified Harris hip score was better in patients undergoing Primary THA with large femoral head as compared to conventional femoral head. The range of movement in all planes was significantly better in the patients treated with large femoral head than the conventional head. Thus based on the result of our study and other studies we conclude that large femoral head is better than conventional head in THA.

Funding: No funding sources

Conflict of interest: None declared

Ethical approval: The study was approved by the institutional ethics committee

\section{REFERENCES}

1. Gupta DL, Lal DM, Aggarwal DV, Rathor DLP. Assessing functional outcome using modified Harris hip score in patients undergoing total hip replacement. Int J Orthop Sci. 2018;4(2):1015-017.

2. Karachalios T, Komnos G, Koutalos A. Total hip arthroplasty: Survival and modes of failure. EFORT open Rev. 2018;3(5):232-39.

3. American Joint Replacement Registry-Annual Report. 2016:16-20.
4. Norwegian Arthroplasty Register. Acta Orthop Scan. 2003;74(5):514-24.

5. Zagra L, Gallazzi E. Bearing surfaces in primary total hip arthroplasty. EFORT open Rev. 2018;3(5):21724.

6. Triclot P, Gouin F. Update - "Big-head": The solution to the problem of hip implant dislocation? Orthop Traumatol Surg Res. 2011;97(4):42-48.

7. Muratoglu O, Bragdon C, O'Connor D, Perinchief R, Estok D, Jasty M, Harris W. Larger diameter femoral heads used in conjunction with a highly cross-linked ultra-high molecular weight polyethylene: A new concept. The Journal of Arthroplasty. 2001;16(8):2430 .

8. Hammerberg E, Wan Z, Dastane M, Dorr L. Wear and Range of Motion of Different Femoral Head Sizes. The Journal of Arthroplasty. 2001;25(6):83943.

9. Mulholland SJ, Wyss UP. Activities of daily living in non Western cultures: Range of motion requirements for hip and knee joint implants. Int J Rehabil Res. 2001;24:191-8.

10. Cho M, Choi W, Kim J. Current Concepts of Using Large Femoral Heads in Total Hip Arthroplasty. Hip \& Pelvis. 2016;28(3):134.

11. Banerjee S, Pivec R, Issa K, Kapadia B, Kanuja H, Mont M.Large-Diameter Femoral Heads in Total Hip Arthroplasty: An Evidence-Based Review. The American Journal of Orthopaedics. 2014; 43(11):506-12.

12. Harkess J, Crockarell Jr J. Campbell's Operative Textbook for Orthopaedics. 13th ed. Elsevier. 2017;167-313.

13. Muratoglu O, Bragdon C, O'Connor D, Perinchief R, Estok D, Jasty M, Harris, W. Larger diameter femoral heads used in conjunction with a highly cross-linked ultra-high molecular weight polyethylene: A new concept. The Journal of Arthroplasty. 2001;16(8):2430.

14. Söderman P, Malchau H. Is the Harris hip score system useful to study the outcome of total hip replacement? Clin Orthop Relat Res. $2001 ;(384): 189-197$.

15. Jordan F Schaeffer THM. Effect of Femoral Head Diameter on Risk of Dislocation after Primary Total Hip Arthroplasty. J Arthritis. 2013;02(01):1-4.

16. Singh SP, Bhalodiya HP. Head size and dislocation rate in primary total hip arthroplasty. Indian J Orthop. 2013;47(5):443-48.

17. Amstutz HC, Le Duff MJ, Beaule PE. Prevention and treatment of dislocation after total hip replacement using large diameter balls. Clin Orthop Relat Res. 2004;(429):108-16.

18. Howie D, Holubowycz O, Middleton R. Large Femoral Heads Decrease the Incidence of Dislocation After Total Hip Arthroplasty. The Journal of Bone and Joint Surgery-American Volume. 2012;94(12):1095-1103. 
19. Amlie E, Høvik $\varnothing$, Reikerås O. Dislocation after total hip arthroplasty with 28 and $32 \mathrm{~mm}$ femoral head. J Orthop Traumatol. 2010;11:111-15.

20. Magee T, Schaeffer J, Buck D, Gililland J, Hofmann A. Effect of Femoral Head Diameter on Risk of Dislocation after Primary Total Hip arthroplasty. J Arthritis. 2013;2(1):2167-7921.

21. Kim M, Chung Y, Lee J, Kim C. Measuring the Impact of Femoral Head Size on Dislocation Rates Following Total Hip Arthroplasty. Hip Pelvis. 2017;29(2):91-96.

22. Lavigne, M., Ganapathi, M., Mottard, S., Girard, J. and Vendittoli, P. Range of motion of large head total hip arthroplasty is greater than $28 \mathrm{~mm}$ total hip arthroplasty or hip resurfacing. Clinical Biomechanics. 2011;26(3):267-273.

23. Sultan P, Tan V, Lai M, Garino J. Independent contribution of elevated-rim acetabular liner and femoral head size to the stability of total hip implants. The Journal of Arthroplasty. 2002;17(3):289-92.

24. Burroughs B, Hallstrom B, Golladay G, Hoeffel D, Harris W. (). Range of Motion and Stability in Total Hip Arthroplasty With 28-, 32-, 38-, and 44-mm Femoral Head Sizes. The Journal of Arthroplasty. 2005;20(1):11-19.
25. Campbell's Operative Textbook for Orthopaedics. 13th ed. Elsevier. 2017;167-313.

26. Bartz RL, Noble PC, Kadakia NR, Tullos HS. The effect of femoral component head size on posterior dislocation of the artificial hip joint. J Bone Joint Surg [Am]. 2000;82-A:1300-307.

27. Hammerberg E, Wan Z, Dastane M, Dorr L. Wear and Range of Motion of Different Femoral Head Sizes. The Journal of Arthroplasty. 2010;25(6):83943.

28. Plate JF, Seyler TM, Stroh DA, Issa K, Akbar M, Mont MA. Risk of dislocation using large- vs. smalldiameter femoral heads in total hip arthroplasty. BMC Res Notes. 2012;5(1):553-57.

29. Agarwala S, Mohrir G, Moonot P. Functional outcome following a large head total hip arthroplasty: A retrospective analysis of mid term results. Indian J Orthop. 2014;48(4):410-14.

Cite this article as: Seenappa HK, Naraynamurthy KM, Rashid R, Nadagouda S, Chand V. Is large femoral head a better option than a conventional femoral head primary total hip arthroplasty in Indian population. Int J Res Orthop 2021;7:295-302. 